\title{
COMPUTER SIMULATION OF THE INFLUENCE OF WIND POWER PLANTS ON THE COMPARTMENTS OF THE COMPLEX LANDSCAPE SYSTEM BY THE METHOD OF LIFE CYCLE ASSESSMENT
}

\author{
Volodymyr Pohrebennyk, Dr. Sc., Professor; \\ Mariia Ruda,PhD, Ass.; Taras Boyko, Dr. Sc., Professor; \\ Lviv Polytechnic National University, Ukraine; e-mail: vpohreb@gmail.com, \\ Oleksandr Petrov, Dr. Sc., Professor; \\ AGH, Poland; e-mail: asp1951@gmail.com
}

https://doi.org/10.23939/istcmtm2020.03.

Abstract. It is proposed to apply the concept of life cycle assessment of alternative energy sources, such as wind turbines, to assess their environmental impact. Through simulation modeling, using SimaPro software, obtained was an integrated system of indicators of the impact wind energy systems on the layers subsystems of the compartments of complex landscape systems. A process tree has been built to identify potential impacts, as well as to characterize, weigh, and rank them. Based on the assessment analysis of various environmental impacts, it was determined that significant consequences for the layers of the subsystems of the complex landscape systems compartments usually arise at the stage of transportation, installation, and erection of wind turbines, as well as the removal of individual components or the entire turbine at the end of its operation. It is shown that the study of all the processes alone, starting from the formation and ending with the utilization of landscape-technogenic systems will reveal the possible integrated effects of their impact on the environment.

Key words: Computer Simulation, Environmental Impact; Life Cycle Assessment; Wind Power Plant.

\section{Introduction}

Human activities in the process of manufacturing products or providing services are inevitably associated with environmental impact. Depending on the nature of the product/service, environmental impacts may be different, such as the ozone layer depletion, greenhouse effect, soil acidification or biodiversity loss, and so on. Each product or service goes through a series of development stages that collectively make up their "life cycle" and each of the stages has its specific impact on the environment.

Earth is a closed system of material flows. Moving from one product to another and changing the shape of its state, matter circulates in the ecological system. That is why the total mass of matter does not change, regardless of what humanity produces on Earth, or what service it provides, and the course of material flows and processes occurs linearly. Thus, over an infinitely long period, materials that have passed through the technosphere are returned to the environment again as raw materials.

The life cycle concept considers products/services from the beginning of their physical emergence until the moment of their termination. The life cycle consists of the following stages: raw material extraction, energy production, transportation, primary processing operations, direct product production, packaging, distribution, recycling, and others.

In the process of planning and designing the life cycle of a certain product/service, a systematic approach should be applied that takes into account the interaction of this life cycle with the life cycle systems of other products/services. The output energy flows can be both wastes of the system under study and serve as resources (input flows) to another system. At all stages of the product/ service life cycle, when energy is used and materials are processed, certain environmental pollution occurs.

Optimal management of ecosystem conditions involves the use of advanced technologies in their research which are based on the application of modern expert intelligent information systems. Sustainable development of the region as an integral socioecological-economic system requires an adequate apparatus informing on the state of the natural environment and the corresponding imitation models. At the same time, the prediction should be based on reliable methods for modeling the assessment of ecosystem conditions, which has become the subject of this study.

\section{Literature Data Analysis and Problem}

\section{Formulation}

In recent decades, humanity has faced two conflicting energy problems. On the one hand, this is ensuring the reliability of energy supply, and on the other hand, the prevention of negative effects of energy production on the environment, both in areas where the sources of generation are located and on a global scale [1].

It is a common belief that the use of electrical energy from renewable sources is environmentally friendly. This is not entirely true, since such energy sources have a fundamentally different spectrum of an environmental impact compared to traditional energy 
sources based on different types of fuel, and in some cases, the influence of the latter may be even less dangerous [2]. The environmental impact of non-traditional and renewable energy sources on the environment has been investigated to a much lesser extent today than the technical issues of their use, especially concerning their temporal aspect [3-4].

The problems of modeling environmental processes and systems at various levels have been investigated by many domestic and foreign scientists. A special contribution to this area was made by I.S. Blagun, V.V. Vitlinsky, A.K. Prykarpatsky, V.M. Geyts, M.V. Odrekhivsky, M.I. Skrypnychenko, B.V. Gnedenko, I.M. Kovalenko, A.V. Yatsyk, A.B. Kachynsky, V.I. Muntiyan. However, the analysis of the literature sources has revealed that alternative energy issues are mainly addressed in technical terms by studying the further improvement of the design and technology of the use of wind power plants (wind turbines), or from the economic point of view considering the economic effects of using wind energy, while the effects of wind energy on environmental components have not been sufficiently covered and are hardly considered in environmental research.

Practice shows that to develop such a methodology that could be used to study and model any ecosystems and their states in different regions, an integrated approach should be applied. In particular, this may be the Life Cycle Assessment (LCA) method, based on a series of ISO standards [5-8] and which is one of the leading methods for assessing the potential environmental impacts of wind power stations (wind farms). This approach was used in the studies of European scientists B. Cleary et al. [9], E. Martinez et al. [10], Ch Ghenai [11], T. Toth et al. [12], and in the work of Russian scientists B.V. Ermolenko et al. [13], as well as one of the largest manufacturers of wind turbines - the Danish company Vestas [20]. Not many current life cycle assessment studies exist for wind turbines with high rated power $(600 \mathrm{~kW})$. The available studies [14-21] are different in their scope but show the dominant influence of the material produced on the environmental performance of wind power plants. Some of these assessments also indicate large amounts of the indirectly produced waste.

\section{Studies}

\section{Purpose, Object, and Subject of the}

The Purpose of the Study is to develop a methodological approach to the construction of an integrated system of indicators for assessing the effects of wind turbines on the layers and subsystems of compartments of complex landscape systems (CLS) at all stages of their life cycle (LC) as well as through using simulation.

The Object of the Study were 34 wind turbines of the company Siemens SWT DD-142 in the wind farm with a total capacity of 120 MW with the necessary infrastructure, namely access roads, $110 \mathrm{kV}$ underground cable power lines and $35 \mathrm{kV}$ underground cable networks, distribution points, and a substation, with a total area of 30.6041 ha, the ATLAS VOLOVETS ENERGY LLC being part of the wind park. The site of the Volovets wind farm is located in the northwest of the Transcarpathian region within the boundaries of the Borzhava Polonyny of the Eastern flysch Carpathians.

The Subject of the Study is CLS in which wind turbines operate. CLS is a biological system characterized by the structural and functional unity of the interconnected components and the integrity of the biotic and abiotic components. The biotic component of the environment is integrated into compartments consisting of subsystems of different levels of the organization and a large number of different layers, between which there are close material, energy, and hierarchical connections. The Borzhava Polonyny of the Eastern flysch Carpathians, by definition [22-23], are referred to as CLSs.

Considering the environmental factor is today one of the most important conditions for the life of not only industrial systems of various purposes, such as wind farms, but also of society in general. Sustainable development is first and foremost the conservation and rational use of natural resources. That is why the environmental component should be considered as one of the determining factors in solving the problems of achieving sustainable development and an acceptable level of economic security of both individual business entities and regions and the state as a whole. It can be characterized by a variety of forms of manifestation of environmental impacts, the composition, and intensity of environmental impacts, the nature of the social, economic, physiological, and other consequences of these impacts.

To quantify the consequences of wind turbine impacts in the CLS compartments, the life cycle of wind turbines was analyzed using SimaPro software which is a professional tool for collecting, analyzing, and monitoring the environmental characteristics of products and services. With its help, it is possible to model and analyze complex LCs systematically and understandably.

In particular, SimaPro makes it possible to analyze products taking into account waste management scenarios which can be modeled independently, depending on the selected product/service. The LC contains waste management scenarios with percentages for each stage (for example, recycling, landfilling, etc.) in a general scenario or one scenario for landfilling.

To analyze the environmental impact of a wind turbine in the CLS compartments during its LC, the SimaPro program contains data on the individual components of the wind turbines in the CLS compartments, indicating the materials, components, and processes that 
accompanied them. All the necessary input data were grouped by the relevant stages of the wind turbine life cycle, namely: production - contains the production of raw materials (concrete, aluminum, steel, fiberglass, etc.) for the manufacture of components of the turbine; transportation - covers the transportation of raw materials for the production of wind turbine components, the delivery of components to the installation site during erection works, and the necessary movement of vehicles when equipping a wind farm; installation and erection procedure - includes work on the construction and installation of wind turbines; operation and maintenance the longest stage, covering the period of the wind turbine operation, oil change and use of vehicles for maintenance; dismantling - provides for the final closure of the wind farm after its operating period and subsequent disposal of the generated waste.

\section{Methods of the Study}

The other term, crucial to understanding the holistic approach of the life cycle, is the life cycle assessment. It encompasses all the processes required to fulfill the function provided by a product or service, [24]. At present LCA is used for the following fields of application [25]: infrastructure; process industry; energy production; transportation; heavy industry; consumer goods; livelihood.

The ISO 14040/44 standard defines the concept of life cycle assessment (LCA) as a compilation of inputs and outputs of a production system and their potential environmental impact at all stages of a life cycle - from raw materials extraction and energy production to decommissioning. Therefore, LCA is a combination of the comprehensive environmental characteristics of a product/service/process, where a quantitative measurement of their environmental friendliness is the result of the LCA process [26].

Thus, LCA is a technique for assessing potential environmental aspects and potential aspects associated with a particular product by using: compiling a list of important flow balances; assessing the potential environmental impacts of these flows; interpretation of the results of the previous stages of analysis in terms of the study objectives, etc.

The LCA procedure is governed by the standards: ISO 14040: Principles and Framework, and ISO 14044: Requirements and Guidelines. However, the use of standards does not exclude the subjectivity of assessments in determining the boundaries of analysis (the boundaries of the system), the level of importance of impacts, and the comparison of the strength of impacts of various nature. Therefore, adherence to standards and the use of software products does not guarantee the objectivity of results; therefore, their use for public information requires accurate documentation and independent expert evaluation. The use of the Product Category Rules (PCR), which are regulated by the ISO 14025 standard, more strictly regulates the LCA procedure and provides greater objectivity to the ratings and Environmental Product Declarations (EPD). The preparation of Environmental Product Declarations is an essential application of LCA. In some countries, the practice of their application is very common.

At the European level, LCA standards are refined and supplemented by the ILCD Handbook (2010), which ensures greater consistency and objectivity of environmental impact assessments.

The LCA is the basis of such software products as SimaPro, Gabi, Ecoinvent, Umberto, OpenLCA, LCAPIX, BEES 4.0, TEAM, Athena Impact Estimator, and others. The leaders among commercial LCA software in Europe today are SimaPro and Gabi [27]. The kind of software product to be applied for a particular case is determined by the analyst based on the goals and the object of study.

In addition to multifaceted assessments of LC that give a comprehensive characterization of the impact, the analysis also uses estimates focused on a particular impact, say, carbon footprint (GHG Protocol and ISO 14067) or hydrogen footprint (ISO 14046).

SimaPro software product, which we will use for LCA, supports EPDs, GHG protocol, and ILCD Handbook; it provides for four stages of research:

Stage 1. Determining the goal and scope of the study - beneficiaries and their expectations.

Stage 2. Life cycle inventory (LCI) - the formation of a life cycle model (LC), all environmental inputs and outputs being displayed.

Stage 3. Life Cycle Impact Assessment (LCIA) is a study of the importance of all inputs and outputs in terms of their potential impact. ISO 14040/44 distinguishes the following steps in impact assessment: mandatory stages: classification and characterization; additional stages: normalization, ranking, grouping, and weighting.

Stage 4. Interpretation of the results obtained [26]. According to the European standard for environmental impacts caused by wind turbines, there are seven categories of impacts: abiotic depletion - non-fossil resources (ADP-non-fossil, kg Sbeq); abiotic depletion fossil resources (ADP-fossil, MJ net caloric value); acidification (AP, $\mathrm{kg} \mathrm{SO}_{2}$ eq); eutrophication (EP, $\mathrm{kg}$ $\left(\mathrm{PO}_{4}\right)_{3}-\mathrm{eq}$ ); global warming (GWP, $\mathrm{kg} \mathrm{CO} \mathrm{CO}_{2} \mathrm{eq}$ ); ozone layer depletion (ODP, kg CFC-11eq); formation of a photochemical ozone layer (POCP, $\mathrm{kg} \mathrm{C}_{2} \mathrm{H}_{4} \mathrm{eq}$ ) [28].

The categories of impact are slightly different for different quantification methods. Nowadays, the following methods are most commonly used in practice: ReCiPe Endpoint (E), Impact 2002, Eco-points, Eco- 
indicator, EPS system, MIPS concept, etc. [29]. The categories of harm in many methods are ecosystem quality, human health, and the depletion of natural resources. But they can be very specific depending on the needs of the analysis $\left(\mathrm{CO}_{2}\right.$ absorption, soil change, fossil fuels, etc.) [26].

This study uses integrated indicators to assess the impact of wind turbines on CLS compartments over their life cycle. For this, SimaPro offers a wide range of methods and databases which are considered the most recognized and well-grounded for the analysis of such area.

The stages of the study include the following steps: determining the background of the problem, functional unit description, building a block diagram of the LC, determining the boundaries of the system, Waste scenario, inventory, generating the process tree, classification, characterization, normalization, comparing impacts, determining the environmental index.

Background of the Problem. Due to more environmental concerns and more environmental restrictions, renewable energies are developing fast these days. Wind power is the most cost-effective renewable energy technology producing electricity (except large hydro power) and the fastest growing market with a growth of an average cumulative rate of $28 \%$ over the past five years [30]. And this tendency will continue in the next years. By the end of 2004, the capacity of wind energy installed globally had reached a level of almost 48.000 MW. Europe accounts for $72 \%$ of the total installed capacity (34.205 MW) and $73 \%$ of the annual market growth during 2004 (5,800 MW).

But is this renewable energy technology as "green" (environmentally friendly) as it is always claimed? The argument behind is usually based on the environmental effects of the operation phase of the wind turbine (that will produce electricity with no consumption of fossil fuel and no pollution) excluding the whole manufacturing phase (from the extraction to the erection of the turbine including the production processes and all the transportation needs) and the decommissioning phase.

Functional Unit. The function of the wind turbine is to produce electricity. MWh as a common measure of electricity should be used as the functional unit. However, due to limited time, we chose the electric power that one unit of wind turbine generates during its life span as a functional unit in this study for simplicity. 1 wind turbine of the specified manufacturer [31] produces $7,890 \mathrm{MWh}$ /year, corresponding to a capacity factor (the amount of energy a facility generates in one year divided by the total amount it could generate if it ran at full capacity [32]) of $30.02 \%$, which means $157,800 \mathrm{MWh}$ electricity generated in its life span of 25 years. The figure may vary in different sites due to various wind conditions. Therefore, the functional unit in this study is 157,800 MWh of electricity.

Boundaries of the system. Another important task at the first stage of the LCA is to determine the boundaries of the system under study, as it is important to discard influences that are not essential for the analysis. While the boundaries of the system are defined, the phenomenon of recursion occurs: the extraction of raw materials or energy production requires basic work equipment (machinery, transport, etc.), and they also have their life cycle (endless regression). The exclusion of individual components of the system from consideration may significantly affect the results of the assessment.

Therefore, to avoid mistakes, the LCA practices use two approaches: basic work equipment is not considered at all in the analysis, or only the effects of raw material extraction and transportation are taken into account. Databases such as Ecoinvent and USA InputOutput account for the basic work equipment using the second approach. In the LCA of natural systems, these systems are viewed as economic rather than natural. Therefore, carbon sequestration and land use impacts are not considered at all, but environmental pollution by pesticides is taken into account. The ReCiPe method, which is implemented in SimaPro, is based on this principle of determining the boundaries between natural and economic systems.

The first stage is completed by determining the goal and scope of the study. The next stage of the study, according to the LCA procedure, is a description of the life cycle (Life Cycle Inventory). The following data are required to identify and describe the effects of the LC: information about the object under study to be collected by the analyst (Foreground data) and background data on physical/chemical dependencies and processes (Background data) contained in the literature and Ecoinvent v3 database which is offered together with the SimaPro program.

Most of the data used in our model come from an LCA report realized by Vestas [31] and from the General Specification of the "Siemens SWT DD-142" [33]. Fig.1 shows, as an example, the model generated by the SimaPro program for the turbine under study, which will be discussed further in the "Results" section.

The manufacture of the turbine covers the period from obtaining the raw materials to the completion of the wind turbine. The manufacture of the turbine can be decomposed of the manufacture of the three main parts of the turbine: the tower, the rotor, and the nacelle.

However, as the data for the energy consumption used for each manufacturing process were not available, the total energy consumption has been defined for the whole turbine manufacture and operation and represents 7405 MWh electricity. The total energy consumption 
during the production phase is $7795 \mathrm{MWh}$ [34]. But this figure includes not only the energy needed for the turbine manufacturing and operation but as well the energy needed for the whole processing phase of the raw material. So we have subtracted $390 \mathrm{MWh}$ (a figure that was calculated with the data available in SimaPro) from $7795 \mathrm{MWh}$ to ensure the energy consumption in the raw material is not double-counted. Electricity Denmark B250 (which is a mix-production of the average electricity produced in Denmark) from the database BUWAL250 has been used in SimaPro.

The tower is made of plates of steel and it has been assumed that the tower is made of $100 \%$ steel [31]. Reinforcing steel, at plant / RER S from the database Ecoinvent system process has been used in SimaPro. To manufacture the 105 meters height tower of our turbine considered, 275 tons of steel are needed [33]. The painting of the tower has not been taken into consideration in our model.

The rotor is composed of 3 blades, the hub, and the nose cone. The blade of the Vestas turbine is made of Prepreg that is one kind of glass fiber impregnated with epoxy resin. Prepreg is assumed to be composed of $60 \%$ glass fiber and $40 \%$ epoxy [31]. The epoxy resin I from the database IDEMAT 2001, and Glass fiber reinforced plastic, polyester resin, hand lay-up, at plant/RER $S$ from the database Ecoinvent system process have been used in SimaPro. Blade weight is 6.6 tons but as $10 \%$ of the Prepreg turns into waste due to cut-offs, 7.3 tons of Prepreg is needed for the manufacturing of one blade (2.9 tons epoxy and 4.35 tons glass fiber) [31 \& 33]. There are also a few amounts of carbon fiber in the composition of the blade but as we could not collect data for it, it has been neglected. And one more time, the painting of the blade has not been taken into consideration in our model.

The hub is made of cast iron and weighs 8.5 tons [33] Cast iron, at plant / RER S from the database Ecoinvent system process has been used in SimaPro.

The nose cone is the shell that will recover the hub. The total weight of the hub and the nose cone is 20 tons [32], so the nose cone weighs 11.5 tons. It is constructed of fiberglass-reinforced polyester. Glass fiber reinforced plastic, polyester resin, hand lay-up, at plant / RER S from the database Ecoinvent system process has been used in SimaPro. Again the painting of the nose cone has not been taken into consideration in our model.

The nacelle consists of the nacelle cover, the generator, the gear, the transformer, the yaw system, the electronics. As we will have to change once the generator and the gear during the life-time of the turbine (see the Operation \& Maintenance phase), we model the nacelle as composed of three main components: the generator, the gear, and frame, machinery, and shell (this last unit includes all the nacelle components except the generator and the gear that are treated separately).

The generator weight is given to be 8.5 tons [33]. It is assumed to be composed of $35 \%$ copper and $65 \%$ steel [35]. Copper, primary, at refinery / GLOS from the database Ecoinvent system process and Reinforcing steel, at plant/RER $S$ from the database Ecoinvent system process have been used in SimaPro. A generator is made of much more material like copper and steel (that are however the main materials). But as far as no other more detailed data were available, the above rough model has been chosen.

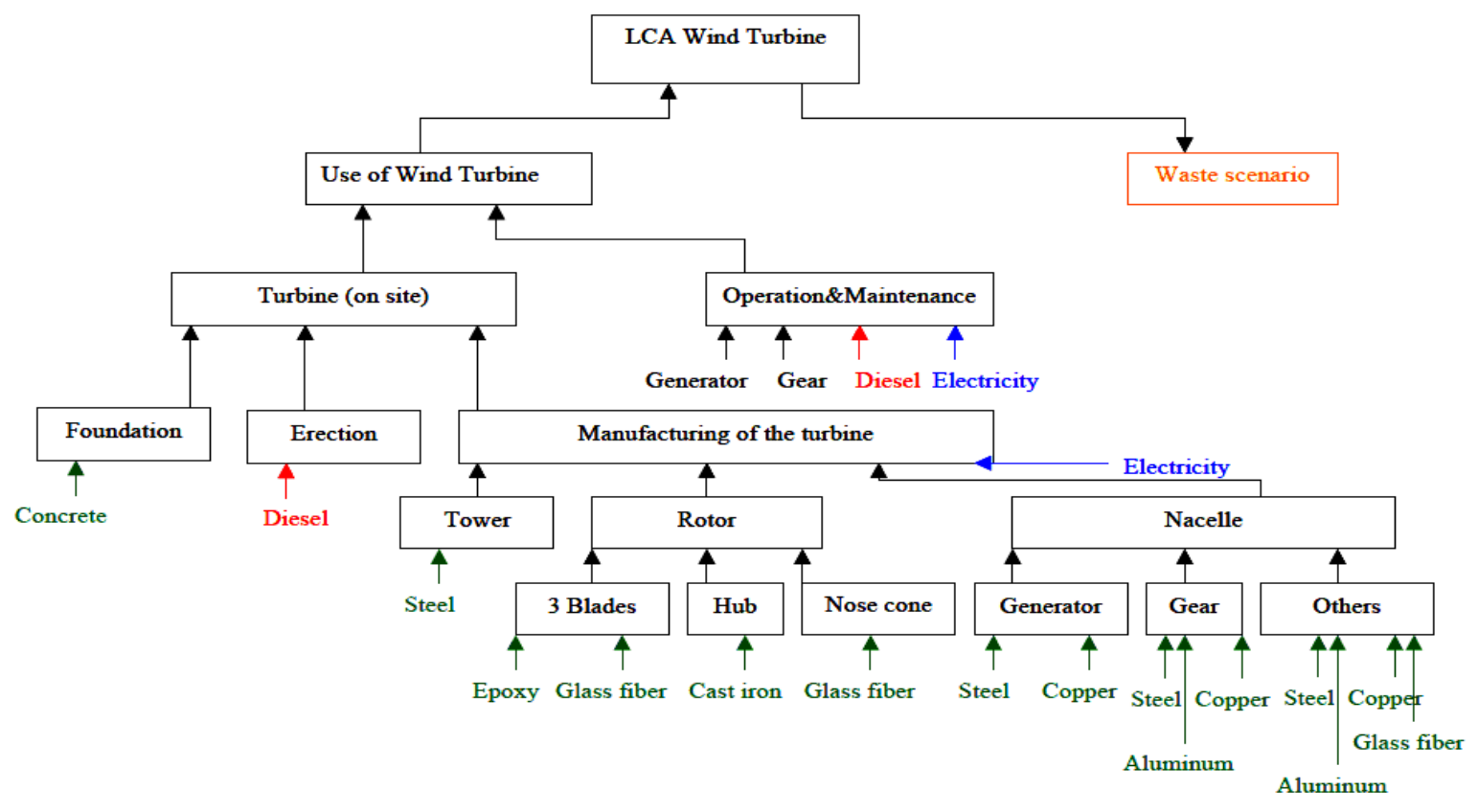

Fig. 1. Model for a wind turbine in SimaPro 
The gear system (called as well gearbox) has a total weight of 23 tons [32]. It is assumed to be composed of $98 \%$ steel, $1 \%$ copper, and $1 \%$ aluminum [36]. Reinforcing steel, at plant / RER S from the database Ecoinvent system process, Copper, primary, at refinery/GLOS from the database Ecoinvent system process and Aluminum, production mix, at plant/RER $S$ from the database Ecoinvent system process has been used in SimaPro.

This unit has a given weight of 37 tons [31]. It is assumed to be composed of $85 \%$ steel, $8 \%$ aluminum, $4 \%$ copper, and $3 \%$ Glass Reinforced Plastic [36]. Reinforcing steel, at plant/RER S from the database Ecoinvent system process, Aluminum, production mix, at plant/RER $\mathrm{S}$ from the database Ecoinvent system process, Copper, primary, at refinery / GLOS from the database Ecoinvent system process and Glass fiber reinforced plastic, polyester resin, hand lay-up, at plant/RER $S$ from the database Ecoinvent system process have been used in SimaPro. This unit is composed of so many different components (nacelle cover, transformer, electronics, shaft...) that all the data for each component were not available. The above model is based on an accounting of the main materials used and their percentage regarding the total weight of the unit.

Three different phases have to be achieved to obtain as a result of an installed turbine in a specific site. First, we need a turbine (that is to say that the turbine manufacturing phase has been completed); then some foundation has to be built on the site; and finally, the different parts of the turbine (tower, rotor, and nacelle) have to be erected and assembled. The foundation is made on-site and consists of filling up a hole (typical size $15 \mathrm{~m} \times 15 \mathrm{~m}$ and $2 \mathrm{~m}$ deep with some concrete reinforced by steel: the total amount of reinforced concrete is 1200 tons [31]. Concrete (reinforced) I from the database IDEMAT 2001 has been used in SimaPro. The energy to realize the excavation of the hole has not been considered. This phase includes the transportation of the different parts of the turbine to the site and the erection of these parts (by a crane) to build up the turbine on site.

The resource used is therefore mainly fuel (diesel) and the amount of diesel has been calculated to be 5382 $\mathrm{kg}$ (as the energy consumption for the Erection\& Transportation is given to be $74 \mathrm{MWh}$, i.e. $266400 \mathrm{MJ}$ [34] and the heating value for diesel is $49.5 \mathrm{MJ} / \mathrm{kg}$ ). Diesel stock Europ S from the database ETH-ESU 96 System process has been used in SimaPro.

The phrase "Use of wind turbine" includes the phase of operation and maintenance of the wind turbine (onsite). The operation of the turbine requires almost no resource since the turbine uses the energy contained in the wind to produce electricity without emitting any kind of pollutant. Nevertheless, some energy is needed for a yaw system operation, which is used for turning the wind turbine rotor against the wind. However, due to the lack of specific data, it is included in the total energy consumption and allocated to the manufacturing phase.

The energy consumption due to the maintenance is mainly fuel consumption as far as maintenance is mainly transportation of the personnel to the site for the regular check-up of the turbine.

The amount of diesel has been calculated to be $1020 \mathrm{~kg}$ (as the energy consumption for the Erection\& Transportation is given to be $14 \mathrm{MWh}$ [34]). Diesel stock Europe S from the database ETH-ESU 96 System process has been used in SimaPro.

Furthermore, the gear and the gearbox are replaced once during the 25 years life-time of the wind turbine. So we have included as "resources" used during the operation and maintenance phase, the gear and the generator (already described before and including the impact of their manufactures).

But as the energy required for their manufacture has been taken into account as a general figure for the manufacture of the whole turbine, $608 \mathrm{MWh}$ of electricity has to be added at this point to make sure that all the resources used for the gear and gearbox manufacture have been properly accounted for (608 MWh corresponds to $8.2 \%$ of the electricity use for the whole manufacturing process of the turbine $(=7405$ $\mathrm{MWh})$ as the weight of the gear and the generator (31.5 tons) corresponds to $8.2 \%$ of the total weight of the turbine (385.5 tons). Electricity Denmark B250 (which is a mix-production of the average electricity produced in Denmark) from the database BUWAL250 has been used in SimaPro. The change of oil and lubricants (required for all the moving parts like the gear) are included in the global energy consumption expressed in $\mathrm{kg}$ Diesel and are not accounted for on their used resource since it is a small use compared to diesel use.

Waste scenario:

- Steel and cast iron - $90 \%$ of the steel and cast iron are recycled and the remaining $10 \%$ is landfilled [31]. Recycling steel and iron/RER S from the database Ecoinvent system processes (Waste type: Steel; Ferro metals), and Steel (inert) to landfill S from the database ETH-ESU 96 System processes (Waste type: Steel; Ferro metals) have been used in SimaPro.

- Copper $-90 \%$ of the copper is recycled and the remaining $10 \%$ is landfilled [31]. Recycling copper as copper, primary, at refinery/GLO $\mathrm{S}$ in the database Ecoinvent system processes. The energy consumption during copper production is $130.3 \mathrm{GJ} /$ ton [37]. Energy consumption for copper recycling is $20 \%$ of production (13\% in Energy \& Recycling [38], for conservation, we use $20 \%$ ). The energy consumption in recycling translated to electricity is $7 \mathrm{MWh}$ Electricity Denmark $\mathrm{B} 250$. Copper (inert) to landfill $\mathrm{S}$ from the database 
ETH-ESU 96 System processes (Waste type: Coppers) have been used in SimaPro.

- Glass fiber and plastics $-100 \%$ of the glass fiber and plastics are incinerated [31]. Disposal, polyethylene terephthalate, $0.2 \%$ water, to municipal incineration / CH S from the database Ecoinvent system processes (Waste type: Plastics) has been used in SimaPro.

- Concrete $-100 \%$ of the concrete is landfilled. Concrete (inert) to landfill $\mathrm{S}$ from the database ETHESU 96 System processes have been used in SimaPro.

Transportation - It has been assumed that the recycling station, landfilling, and incineration plant are situated on average at $200 \mathrm{~km}$ away from the site; i.e. for each ton recycled, $200 \mathrm{~km}$ of transportation is accounted for. Truck 28t B250 from the database BUWAL 250 has been used in SimaPro.

\section{Results of the Studies}

The generation of electricity due to wind does not have a significant negative impact on the environment and the social sphere, also there is a reduction in emissions of greenhouse gases and other harmful substances into the atmosphere. According to the estimates of the Institute of Renewable Energy of the National Academy of Sciences of Ukraine, only due to the planned commissioning of wind farms with a capacity of 16,000 MW by 2030 , the average annual carbon dioxide emissions will not increase by 32 million tons, i.e. annual gas savings will amount to 14.4 billion $\mathrm{m}^{3}$.

However a wind farm, like any other object of economic activities, causes changes in the natural characteristics of the landscape and the properties of its components, which leads to the formation of man-made geocomplexes [39] on the one hand, and on the other hand, achieves several positive environmental results: it is a source of renewable energy and prevents the depletion of natural non-renewable resources.

The study of the wind farms' impacts on environmental components was carried out taking into account a number of their parameters, including technical characteristics. According to the intentions of the Customer and the design solution, the designed wind farm consists of separate sections and placement of facilities and equipment on them. The main equipment of the project is wind turbines. Considering wind and weather conditions in the territory of the planned activities, as well as noise, vibration, and other characteristics, the customer selected a wind turbine manufactured by Siemens SWT DD-142. The wind turbines are certified according to ISO 9001 and IEC 61400-12-1.

Stationary wind farm objects include wind farm operation management system and facilities, repair and maintenance base facilities, distribution points with power equipment and engineering communication utilities, foundations of towers, wind turbine towers, supports, and aerial and underground cable lines, access roads, other auxiliary facilities and engineering communications necessary for the operation of the wind farm, as well as ensuring the life support of the staff.

When placing a wind turbine, the following is taken into account: the availability of roads for transporting equipment and the possibility of arranging access to the wind turbines, in particular the maximum use of the existing infrastructure to minimize the environmental impact. The positioning of the wind turbines takes into account the dominant wind directions.

The distances between the turbines were determined, based primarily on the results of the analysis of the wind characteristics of the territory and considerations for optimizing the location of the wind turbines to reduce environmental impacts, as well as taking into account the visual impact on the population of the nearest settlements and tourists.

In the territory where the wind turbines are located, it is supposed to temporarily arrange construction sites for installation and maintenance of the facilities. Another category is the land plots which are temporarily used to store the parts of the structures. Along the wind turbine rows, there will be located underground cable and communication lines, and technological roads, which is reflected in the schemes of engineering networks.

Boundaries of a Wind Turbine Research System are the production of materials and equipment necessary for the manufacture of components of the turbine and auxiliary structures, platforms (concrete, aluminum, steel, fiberglass, etc.); the usage of the existing roads for transportation of the wind turbine components and other equipment from the place of their production to the place of installation of the equipment utilizing specialized trucks with trailers; installation of the wind turbines using cranes; a land plot of 1.25 hectares temporarily used to store parts of the structures; visual impact of wind turbines with a height of up to $150 \mathrm{~m}$ (taking into account the rotation of the blades); shimmering shadow; the noise and vibration generated by the rotation of the blades and the operation of the generators; electromagnetic radiation of the designed aerial and cable power lines and transformer substation; impact on the water bodies.

The results of the first stage made it possible to determine the goal and scope of the research. The goal of the analysis is to calculate integrated indicators of the impact of the wind turbine during its life cycle on the CLS compartments. The scope of the research - the indicators obtained will be used to model the impact on the subsystems and layers of the CLS compartments.

According to the LCA procedure the goal and scope defined in the work, as well as the model 
generated by the SimaPro program (Fig. 1) made it possible to continue the life cycle description of the wind turbine and move to its inventory.

The inventory is Then completed under the defined limits and the data presented in Table. 1 The inventory phase is the core of an LCA and is a common feature of any LCA. During this phase all the material flows, the energy flows, and all the waste streams released to the environment over the whole life cycle of the system under study are identified and quantified. The final result of the inventory analysis is an inventory table. The inventory phase has four separate sub-stages:

- Constructing a process flow chart (so-called process tree).

- Collecting the data.

- Relating the data to a chosen functional unit (allocation)

- Developing overall energy and material balance (all inputs and outputs from the entire life cycle) - an inventory table.

To develop a life cycle it is best to start from the product itself and then follow all upstream and downstream life stages. Then we have to determine which part of the total emissions and material consumption should be attributed to each specific product. The same applies to multi-input processes. Petrol production can serve as an example of a multi-output process.

The problem of how to divide emissions and material consumption between several products or processes is called allocation. Several methods have been developed to deal with allocation.

Substitution of Allocation - no allocation. As allocation always require more or less subjective decisions, ISO recommends avoiding allocation if possible. This can be done by extending the system boundaries i.e. by including processes that would be needed to make the same by-product conventionally.

According to estimates by the US National Renewable Energy Development Laboratory (NREL), zones of permanent and temporary exposure are distinguished at all stages of the life cycle of wind farms. Zones of permanent exposure make up 1-2\% of the total area occupied by wind farms. Temporary exposure zones occupy from 1 to $6 \%$ of the territory of the wind farm; at the same time, those sections of wind farm sites that remain outside the influence of the construction can be used for other purposes, for example for growing crops, or for grazing, or recreation. This is an additional gain resulting from the process associated with the analyzed product. This fact should be reflected in the main product's environmental profile. Then the environmental load at the stage of production and transportation of wind turbines, which is avoided as a result of other positive factors, can be subtracted from the total environmental load. Thus, it is possible to calculate a part of the emissions and consumption of materials for which the main product is responsible, and the rest can be attributed to the prevention of undesirable environmental impact.

A typical Life Cycle Assessment inventory table consists of a few hundred or more items. They might be grouped into categories: raw materials, emissions to air, water, soil, solid emissions, non-material emissions (noise, radiation, land use), etc. An inventory table is a basis for the next step of LCA - impact assessment. The data from an inventory table has to be processed to attain a higher level of aggregation. Ideally, the aggregation process results in a meaningful single score.

Based on the inventory, under the defined limits and the data presented in the Table. 1, SimaPro program generates a process tree to identify potential impacts (Fig. 1).

Figure 1 shows the wind turbine life cycle process tree, based on the data obtained from the Environmental Impact Assessment Report Construction of a $120 \mathrm{MW}$ wind farm on the territory of the Volovets village council of Volovets district and on the territory of the Bereznyky, Dusyno, Nelipyno, and Tybava village councils (outside the settlements) Svalyava district of Transcarpathian region No. 2018821379 of 5 February 2018. [40].

Figure 2 shows a typical process block that is necessary for calculating an environmental index and containings material, process or life stage - here: Wind turbine, Quantity - here: one piece 1, Value of the currently calculated quantity - here: partial environmental index for this impact and an environmental "thermometer" shows the contribution of a process to the environmental index.

The calculation is made for the element of the wind turbine life cycle. To analyze the specific stages and their impact on the final output, the "use of wind turbine" flow chart was investigated. The cut-off value was set as $4 \%$ and the pointers have the width according to their significance in the final result.

Having examined the chart, it was observed that energy consumption (especially from coal) expressed as electricity Ukraine B250 has a major impact on the environment $(57.5 \%)$. It can be explained by its affecting the fuel consumption and thus resources mining as well as emission increase (greenhouse gasses, respiratory inorganics, etc.) or carcinogens production.

As mentioned earlier in the results Chapter, energy is used for the indispensable processes as manufacturing of different wind turbine parts or transport.

Other stages of the process which have a significant effect on the output are the production of copper and reinforcing steel, having an impact of $13.8 \%$ and $11.5 \%$ respectively. It has to be also pointed out that operation and maintenance processes are of significance as well as influencing the total output by $11 \%$. 


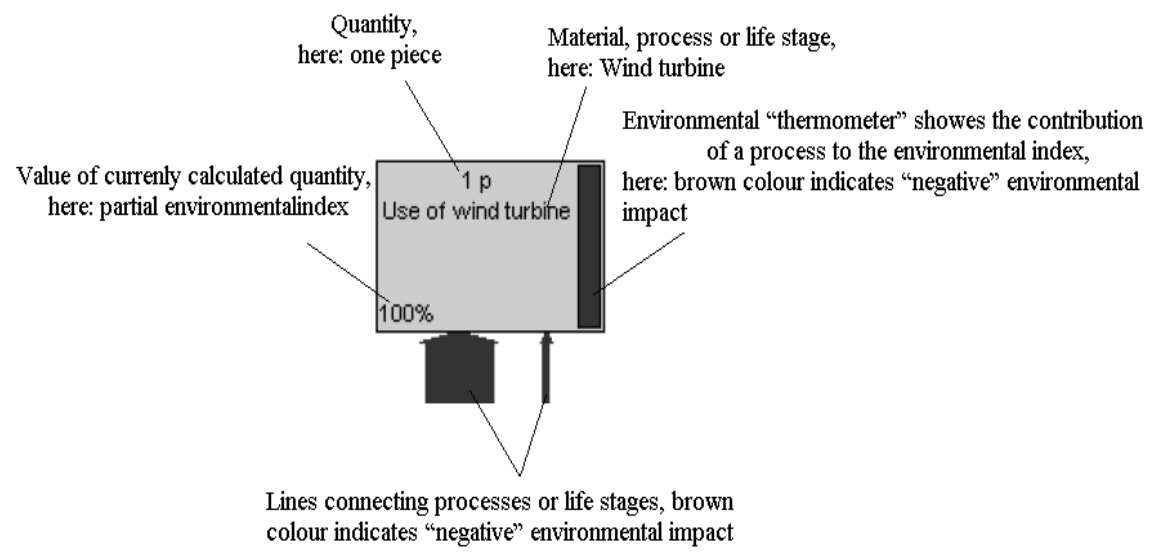

Fig. 2. A process box for the calculation of an environmental index

The first step to reaching higher aggregation of the data is to classify them. The third stage of the study begins with the classification, namely the environmental impact assessment of the wind turbine life cycle.

Classification. Inflows and outflows from the life cycle are gathered in many groups representing the chosen impact categories. The inventory table is rearranged in such a way that under each impact category, all the relevant emissions or material consumption are listed (qualitatively and quantitatively).

The common source of uncertainty here is the lack of a universally accepted appropriate official list of environmental impacts to consider. Nevertheless, as a result of numerous already performed LCAs, a "standard", a list of environmental impacts that should be treated does exist. These are all broadly recognized environmental problems such as resource depletion, toxicity, global warming, ozone depletion, eutrophication, acidification, etc. The choice of impact categories is subjective. It should be adjusted to ensure a good representation of the environmental burden caused by a product, as the outcome of the LCA strongly depends on the choice of impact categories. The list should, if possible, be made already as a part of the goal and scope definition. Many other possible impact categories may be important in some situations, especially on the local scale, and then should be included. Examples are radiation, final solid waste load, noise, smell, and landscape degradation.

Some outputs can be allocated to more than one category, e.g. $\mathrm{NO}_{2}$ causes both acidification, eutrophication, and toxicity.

Thus when performing an LCA, all the emissions and the resource consumption which enter or leave a life cycle are translated into the environmental problems that they potentially may contribute to. The two terms environmental effects and life cycle both need to be properly understood.

After multiplication, all emissions are expressed in the same unit, kilograms.
Environmental effects are the consequences of physical interaction between a system studied and the environment. In practical use, all environmental effects are represented by several categories of environmental problems. The most commonly used are Resource depletion; Global warming; Ozone depletion; Human toxicity; Ecotoxicity; Photochemical oxidation; Acidification; Eutrophication; Land use; Others (including solid waste, heavy metals, carcinogens, radiation, species extinction, noise).

In the previous step, substances contributing to the impact categories were taken from an inventory table and ascribed to a certain group. However, different substances among one group contribute differently to the impact category. During the characterization step, the relative strength of the unwanted emission is evaluated and contributions to each environmental problem are quantified. What is needed here is a single number for each category.

The computational procedure used for aggregating the data among one impact category may be explained by the example for global warming. The characterization can be performed based on environmental models, which allow us to compare different substances contributing to the same environmental problem. This is done by applying so-called equivalence factors. An equivalence factor indicates how many times more a given compound contributes to a problem in comparison to a chosen reference substance. In the case of global warming, $\mathrm{CO}_{2}$ is chosen to be the point of reference. All the other substances causing an enhanced greenhouse effect are given a coefficient indicating how many times more or less these compounds contribute to the effect. For example, methane has an equivalence factor of 11 , which means that $1 \mathrm{~kg}$ of methane causes the same greenhouse effect as $11 \mathrm{~kg}$ of carbon dioxide. The result is expressed in the equivalent amount of $\mathrm{CO}_{2}$. When the equivalence has been calculated all the figures in the impact category have a common unit and can be added up. 


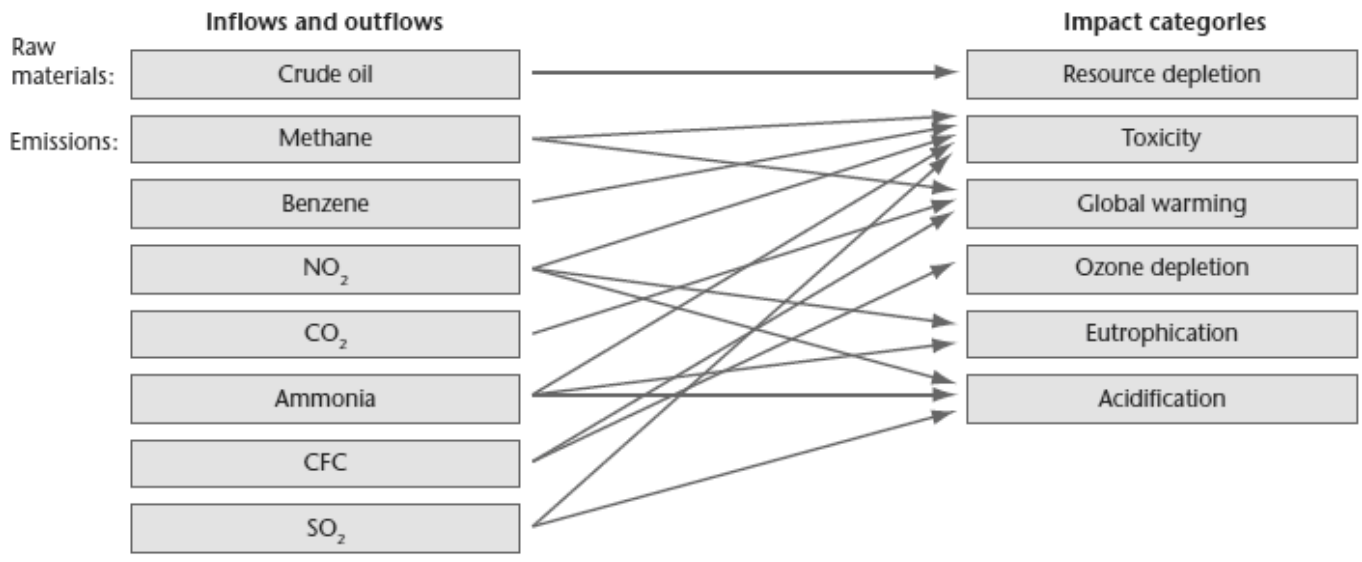

Fig. 3. Relations between emissions and impact categories. To the left are raw materials used (top) and pollutants emitted (bottom) during the life cycle of a product. To the right are the impact categories to which these emissions contribute. The figure illustrates that one emission may contribute to several impacts and that several emissions contribute to the same impact

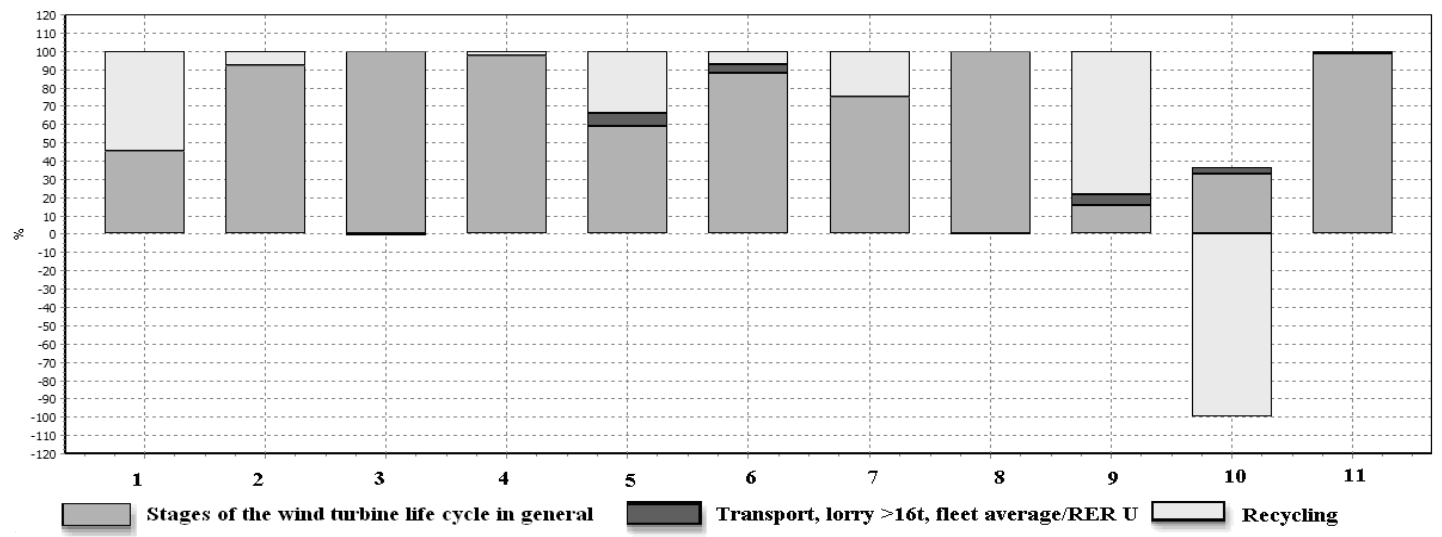

Fig. 4. Characterization of the impacts of the life cycle of a wind farm according to the methodology Eco-indicator'99: 1 - Carcinogens; 2 -Resp. organic; 3 -Resp. inorganic; 4 -Climate change; 5 -Radiation; 6-Ozone layer; 7 -Ecotoxicity; 8-Acidification/Eutrofication; 9 -Land use; 10 -Minerals; 11 - Fossil fuels

The electricity consumed during the manufacture of the wind turbine is the largest contributor to climate change (Figure 4) with $85 \%$ out of a total of 1.58 DALY. This is because electricity production in Ukraine is mainly based on the use of coal as fuel [35], which results in carbon dioxide emissions. Due to the reduction of coal in the primary energy sources, the current impact on climate change is smaller than the LCA model presents. The production of reinforcing steel is the second-largest contributor, however, very minor compared to electricity from coal. The recycling of steel and iron from the wind turbine has a positive impact on climate change since it substitutes production of 334 tons of iron with a reduction in energy consumption.

The impact of the use of wind turbines amounts to 2.14 DALY. However, implementing the waste scenario (- 0.883 DALY) decreases this value to the total impact of 1.25 DALY (by $41 \%$, see Figure 4). Electricity from coal contributes most to the carcinogenic effect, followed by steel production and copper production
(Figure 4). Because recycling includes all steel and iron. The reduction of carcinogens in recycling steel and iron (0.41 DALY) is larger than the production of reinforcing steel (0.38 DALY). The main substances responsible for this are emitted to water Arsenic ions (0.81 DALY) and unspecified metallic ions (0.028 DALY), to air unspecified metals (0.342 DALY), Cadmium (0.06 DALY), and Arsenic (0.27 DALY).

Electricity from coal is the largest contributor to respiratory inorganics (Figure 4). The concrete for the wind turbine's foundations has serious impacts on respiratory systems. The particulates, nitrogen dioxide, and sulfur dioxide $(2.33,1.65$, and 1.51 DALY respectively) are the main threats to human respiratory health. Using the waste scenario decreases the emissions of the inorganic substances by $15.4 \%$ making it the total impact of 5.91 DALY.

Fossil fuels as coal, oil, and gas, are mainly used to generate electricity. The production of metal, e.g. steel and iron is very energy-consuming. Therefore, the 
production of reinforcing steel becomes the third largest fossil fuel user. The transportation of raw materials and components of the wind turbine and the erection consume a substantial amount of diesel which is expressed in Figure 4 as crude oil.

Respiratory organics. The waste scenario is not helpful in this case as it contributes to the negative environmental impact as well by $5,93 \%$. The total emissions amount 33,2E-4 and the main ones are nonmethane volatile organic compounds $(25,2 \mathrm{E}-4)$ as well as methane and unspecified and aromatic hydrocarbons all amounting 7,45E-4.

The reduction of the radiation amounts 16,5\% while using the waste scenario with the total impact caused by the wind turbine of 3,79E-3. It is caused mostly by Radon- 222 and Carbon- 14 both present in the air. Their radiation amounts $2,55 \mathrm{E}-3$ and $1,22 \mathrm{E}-3$ respectively.

Ozone layer. This category is the second one on which the waste scenario has a negative impact as it contributes to $7,34 \%$ in the total impact, which amounts to 5,27E-4. It is caused mainly by one substance bromotrifluoromethane (BTM), known as well as Halon 1303, whose impact amounts 5,02E-4 D.

Ecotoxicity. It is the second biggest positive impact of the waste scenario on the final result. It reduces the environmental impact of $47,8 \%$. After that total impact amounts 2,32E6 PAF $\times \mathrm{m}^{2} \times$ yr and the biggest contribution in it have unspecified metals $(1,25 \mathrm{E} 6)$ as well as Nickel, Zinc $(6,33 \mathrm{E} 5$ together), and Lead $(9,64 \mathrm{E} 4)$, all contained in the air.

Acidification/Eutrophication. The waste scenario has a small impact on reducing the negative one of the use phase. It decreases the impact by $4,07 \%$ making it $1,38 \mathrm{E} 5 \mathrm{PDF} \times \mathrm{m}^{2} \times \mathrm{yr}$ in total. The substances responsible for that number are nitrogen oxides and sulfur oxides amounting 1,06E5 and 2,88E4 respectively.

Land use. The waste scenario is very helpful in this case as it minimizes the negative impact of $32,3 \%$, so the total impact amounts to $3,1 \mathrm{E} 4 \mathrm{PDF} \times \mathrm{m}^{2} \times \mathrm{yr}$. It is influenced mainly by industrial area occupation $(1,3 \mathrm{E} 4)$ and transformation to the industrial area $(9,18 \mathrm{E} 3)$. It needs to be said that thanks to the waste scenario the dumpsite occupation is reduced by $1,46 \mathrm{E} 4$ and influences the most the impact decrease.

Minerals. This category is influenced by the waste scenario at most. It decreases the negative impact of 79,1\% and makes it 1,01E5 MJ surplus in total. Thus, the negative impact is caused mainly by two minerals: nickel $(1,98 \%$ in silicates, $1,04 \%$ in crude ore); copper $(0,99 \%$ in sulfide, $\mathrm{Cu} 0,36 \%$ and $\mathrm{MO} 8,2 \mathrm{E}-3 \%$ in crude ore). They amount 6,47E4 and 3,68E4 MJ surplus respectively.

As we can see the waste scenario has different impacts in each category, of which three can be marked out as the most influenced ones: Mineral, Ecotoxicity, and Carcinogens. It is caused by the fact that almost $80 \%$ of wastes (excluding concrete) were recycled. That allowed reusing received minerals, mainly copper, iron, and aluminum, and decreased their mining but also delimited the emission of elements such as Cadmium, Nickel, Lead, or Arsenic - produced during that process.

Unfortunately, the waste scenario is not just improving the cycle, but it has a negative impact as well. This can be explained by the fact that during the recycling process many gases are emitted, which in consequence can lead for instance to ozone layer reduction.

Characterization is easy if all substances contributing to each impact category are known and a reference substance, as well as equivalence factors, have been defined. For many of the environmental impacts, the equivalence factors remain controversial concerning the methodology by which they are calculated. This applies especially to the categories which are difficult to describe, e.g. "human health". Nevertheless, there are established equivalence factors for the main environmental problems (Table 1).

Table 1

Equivalence factors for environmental impacts

\begin{tabular}{|c|c|c|}
\hline $\begin{array}{c}\text { Classification of } \\
\text { environmental } \\
\text { impact }\end{array}$ & \multicolumn{2}{|c|}{$\begin{array}{c}\text { Equivalence factor and reference } \\
\text { substance }\end{array}$} \\
\hline Ozone depletion & $\begin{array}{c}\text { Ozone Depletion } \\
\text { Potential }\end{array}$ & $\begin{array}{c}\text { CFC-11 } \\
\text { equivalents }\end{array}$ \\
\hline Acidification & $\begin{array}{c}\text { Acidification } \\
\text { Potential }\end{array}$ & $\begin{array}{c}\mathrm{SO}_{2} \\
\text { equivalents }\end{array}$ \\
\hline Eutrophication & $\begin{array}{c}\text { Eutrophication } \\
\text { Potential }\end{array}$ & $\begin{array}{c}\text { Phosphate } \\
\text { equivalents }\end{array}$ \\
\hline $\begin{array}{c}\text { Photochemical } \\
\text { smog creation }\end{array}$ & $\begin{array}{c}\text { Photochemical } \\
\text { Ozone Creation } \\
\text { Potential }\end{array}$ & $\begin{array}{c}\text { ethylene } \\
\text { equivalents }\end{array}$ \\
\hline
\end{tabular}

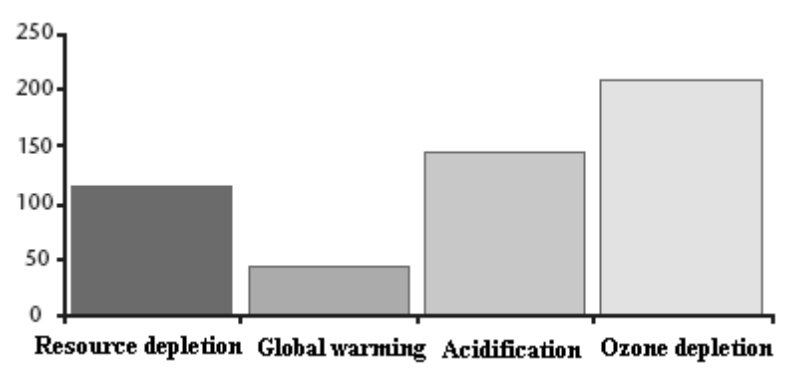

Fig. 5. Environmental profile of the entire wind turbine life cycle

The contribution to an environmental impact is calculated for any substance if an equivalence factor is available. The final result of the characterization step is a list of potential environmental impacts. This list of effect scores, one for each category, is called the environmental profile of the product or service.

In two graphs, Figs. 5 the environmental profiles of wind turbines are shown. These are sets of four single 
scores, one for each of four impact categories: resource depletion, global warming, acidification, and ozone depletion. Figure 6 presents single time estimates divided into four life cycle stages: manufacture, use, transportation, and disposal. It allows us to identify immediately the life cycle phases which have a significant environmental impact. For example, manufacturing contributes greatly to resource depletion. The results from the characterization step cannot be compared since they are usually presented in different units $\left(\mathrm{CO}_{2}\right.$ eq., $\mathrm{SO}_{2}$ eq., CFC-11eq, etc.). From a normalized environmental profile, for example, we can conclude that the respiratory inorganic is $0.052 \%$ of all $\mathrm{CO}_{2}$ equivalents in the life cycle of a wind turbine. Thus, we can say that the life cycle of wind turbines contributes more to global warming than to the destruction of the ozone layer and almost does not affect the flora in the region of construction and operation of wind turbines.

Normalization is performed to make the effect scores of the environmental profile comparable. The normalized effect score is the percentage of a given product's annual contribution to that effect in a certain area [40]:

$$
\begin{gathered}
\text { Normalized effect score }= \\
\frac{\text { annual contribution to that effect in a certain area }}{\text { effect score for a given category }}
\end{gathered}
$$

Figures 5 do not indicate, however, which impacts are of the highest priority, i.e. one cannot say that global warming is a more serious environmental problem than ozone depletion nor the other way around. The environmental profile is only put in a broader context, which makes the interpretation easier.

The lack of relevant figures representing annual contributions to environmental problems is the main difficulty in the normalization step. As can be observed there are two categories that are of greatest importance both from the total impact and waste scenario significance.

Respiratory inorganics such as nitrogen and sulfur oxides and many more have the largest impact on the environment with the total amount of 454 points. They are emitted mostly during the fuel burning. However, it has to be pointed out that the waste scenario is the most significant as far as this category is concerned. Even though minerals' impact is decreased by almost $80 \%$ and inorganics by 'just' 15 , the final output shows that the latter amount is bigger when compared with a common unit.

The second biggest environmental impact is fossil fuels -365 points. This is caused mainly by the use of electricity during the whole process, which is produced from coal in the first place, but also from oil and gas. The contribution of alternative resources (hydro, uranium) is minor. The consumption occurs in the very early stage of the process but does influence the further ones where the consumption is highest - manufacturing of the turbine's parts and transport.

The high impact on climate change is also alarming. It should be regarded as global warming which is caused by greenhouse gases like carbon dioxide or methane and can result in the change of sea level, precipitation distribution, or increased intensity of weather disasters such as hurricanes.

Weighting is the most difficult, subjective, and contradictory stage of assessment because it is based not on the natural sciences but subjective considerations. To compare the effects, weighting factors are used by default which is determined by the following methods: by Expert Group Decision - Eco-indicator 99 and ReCiPe methods; method of accounting for distance from the target - Ecological Scarcity methods; following monetary damage assessment - EPS 2000 method.

An alternative approach to comparing impacts is proposed by Hofstetter et al. (1999) [41-44]. This approach is implemented in SimaPro. It consists of comparing the environmental friendliness of products/processes/services for all possible combinations of weighting factors for three categories of harm: human health, the quality of ecosystems, and resources. For each combination of weighting factors - the corresponding point of the comparison triangle - the sum of these coefficients is $100 \%$.

For the Eco-indicator'99 Method, it is accepted that the impacts on health and ecosystems are twice as important as the impact on resources, according to this, the weighting factors are $40 \%, 40 \%$, and $20 \%$ [41]. The program calculates the environmental load for all possible values of the weighting factors. If the comparative assessment of the environmental friendliness of the products under consideration is affected by the ratio of the weight of the comparison criteria, then both alternatives are displayed in the comparison triangle with the conditions for the occurrence of their advantage being reflected (Fig. 6).

Ranking impact categories in terms of their environmental impact makes a clear distinction between the weighting and all of the previous phases. The latter use empirical knowledge of environmental effects and their mechanisms, while the weighting relies mainly on preferences and social values. In practice, the weighting is performed by multiplying a normalized environmental profile by a set of weighting factors, which reflect the seriousness of a given effect. One of the ready-made methods, Eco-indicator 95, can serve an example of a defined set of weighting factors.

As can be concluded from the table, the highest priority is given to ozone layer depletion and emissions of pesticides. If each impact category is provided with a factor according to its environmental significance, and environmental profile can be expressed in a single environmental index. An environmental index is a sum of 
the numbers, which a weighted environmental profile consists of. Once the environmental indices are calculated, comparisons of products are easy. Let us assume that product $\mathrm{A}$ is represented by an environmental index of 5 and product $\mathrm{B}$ has an environmental index of 10 . One can conclude that $\mathrm{A}$ is twice as environmentally friendly as $\mathrm{B}$. The main difficulty lies, however, in the fact that there is no broadly accepted methodology for establishing weighting factors. For the time being it is difficult to rank environmental problems without running the risk of criticism.

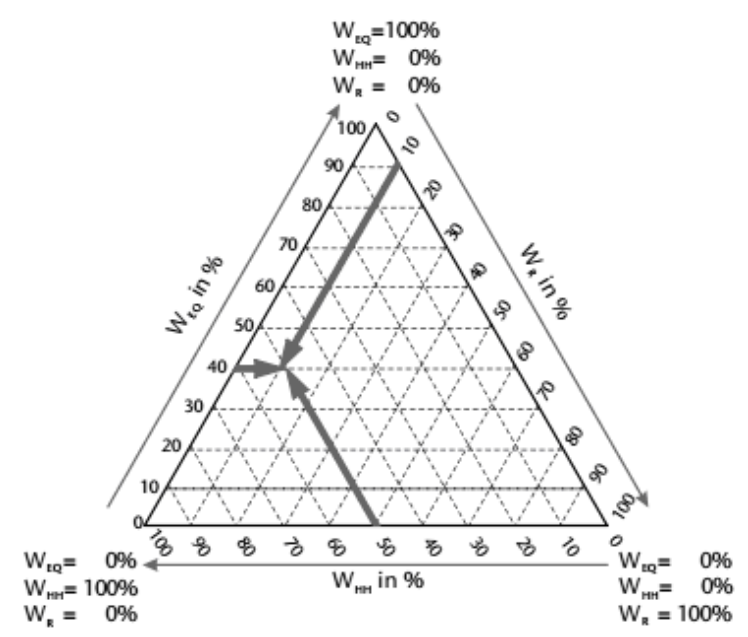

Fig. 6. The weighting triangle: $W_{E Q}-$ Weighting factor for the damage to ecosystem quality; $W_{H H}-$ Weighting factor for the damage to human health; $W_{R}$-Weighting factor for the damage to energy resources;

$$
W_{E Q}+W_{H H}+W_{R}=100 \%
$$

Then follows the critical issue: what should be considered an environmental problem. In the Ecoindicator approach three damage categories, so-called endpoints, are distinguished: Human Health, Ecosystem Quality, and Resources.

The three categories are not sufficiently self-explanatory, and a description of what is included in each of the three terms is necessary for building up the methodology.

The environmental sources for such damages include e.g.:

- Infectious diseases, cardiovascular and respiratory diseases, as well as forced displacement due to climate change.

- Cancer as a result of ionizing radiation. depletion.

- Cancer and eye damages due to ozone layer

- Respiratory diseases and cancer due to toxic chemicals in the air, drinking water, and food.

These types of damages represent important threats to Human Health caused by emissions from product systems. The damage category is, however, far from complete. For instance, health damage from emissions of heavy metals such as $\mathrm{Cd}$ and $\mathrm{Pb}$, of endocrine disrupters, etc. as well as health damages from allergenic substances, noise, and odor are not yet modeled in Ecoindicator 99 .
Ecosystems are very complex, and it is very difficult to determine all damage inflicted upon them. An important difference compared with Human Health is that even if you could, you are not concerned with the individual organism, plant, or animal. The species diversity is used as an indicator of Ecosystem Quality. You can express the ecosystem damage as a percentage of species that are threatened or that disappear from a given area during a certain time.

For ecotoxicity, Eco-indicator 99 uses a method developed in the Netherlands for the Dutch Environmental Outlook [46]. This method determines the Potentially Affected Fraction (PAF) of species concerning the concentration of toxic substances. The PAFs are determined based on toxicity data for terrestrial and aquatic organisms like microorganisms, plants, worms, algae, amphibians, mollusks, crustaceans, and fish.

The PAF expresses the percentage of species that are exposed to a concentration above the No Observed Effect Concentration (NOEC). A higher concentration caused a larger number of species that are affected. The PAF damage function has a typical shape as shown in figure 14. A Logistic PAF-curve expresses the potentially affected fraction of species at different concentrations of a substance. When a chemical is emitted in an area, its concentration in the area will increase temporarily. This change in concentration will cause a change in the PAF value. The damage caused by the emission of this substance depends on the slope of the curve in a suitably chosen working point.

Being based on NOEC, a PAF does not necessarily correspond to observable damage. Even a high PAF value of $50 \%$ or even $90 \%$ does not have to result in an observable effect. PAF should be interpreted as toxic stress and not as a measure to model the disappearance or extinction of species.

For land use, Eco-indicator 99 also uses the Potentially Disappeared Fraction (PDF) as an indicator. In this case, however, you do not consider target species but all species. The damage model is rather complex, and include four different models:

- The local effect of land occupation.

- The local effect of land conversion.

- The regional effect of land occupation.

- The regional effect of land conversion.

The local effect refers to the change in species numbers occurring on the occupied or converted land itself, while the regional effect refers to the changes in the natural areas outside the occupied or converted area. The regional effect was first described by [46]. The data for the species numbers per type of land-use and some of the concepts used for the local effect are based on [47].

The data on the species numbers are based on observations, and not on models. The problem with this type of data is that it is not possible to separate the influence of the type of land use from the influence of emissions. For this reason, special care must be taken to avoid double counting of effects which are included in 
land-use and which could be included also in other damage models.

The Ecosystem Quality damage category is the most problematic of the three categories, as it is not completely homogeneous. As a temporary solution, one may combine PAF and PDF.

In the case of non-renewable resources (minerals and fossil fuels), it is obvious that there is a limit on the human use of these resources, but it is rather arbitrary to give data on the total quantity per resource existing in the accessible part of the earth crust. The sum of the known and easily exploitable deposits is quite small in comparison with current yearly extractions. If one includes occurrences of very low concentrations or with very difficult access, the resource figures become huge. It is difficult to fix convincing boundaries for including or not-including occurrences between the two extremes, as quantity and quality are directly linked.

To tackle this problem, the Eco-indicator methodology does not consider the number of resources as such, but rather the qualitative structure of resources.

Chapman and Roberts [48] developed an assessment procedure for the seriousness of resource depletion, based on the energy needed to extract a mineral concerning the concentration. As more minerals are extracted, the energy requirements for future mining will increase. The measure of damage used in the Ecoindicator for resource extraction is based on this work. It is the energy needed to extract a $\mathrm{kg}$ of a mineral in the future. Much of the data is supplied by [49].

The Eco-indicator values for a certain impact are expressed as a sum of impacts for each of the three categories. Each of the impact categories is expressed in one unit. Impact on human health is expressed as DALY, Disability-Adjusted Life Years, that is the number of years of life lost and the number of years lived disabled. Impact on ecosystem quality is expressed as the loss of species over a certain area during a certain time PDF $\times$ $\mathrm{xm}^{2} \times$ year. The depletion of resources is expressed as surplus energy needed for future extractions of minerals and fossil fuels.

\section{Conclusions}

The goal of assessing the life cycle of wind turbines has been fully achieved through this study. We analyzed the entire life cycle starting from the manufacturing phase to the disposal phase and established all the environmental effects associated with the wind turbine throughout its whole lifetime. The waste scenario is a very important phase of the life cycle of the wind turbine. With the recycling of the materials, we can reduce the negative environmental impacts greatly. The manufacturing phase is very crucial in the life cycle of the wind turbine because it yields the biggest environmental impacts. This is particularly due to the type of electricity used. The more "green" the source of electricity used in the manufacturing phase of the wind turbine; the less the environmental impacts of the wind turbine.

The analysis demonstrated that although most of the products have been recycled and minerals could have been used again, it is still fossil fuels that influence the resource the most and this matter should be considered accordingly in the system improvement.

It was difficult to tell which specific process was energy-intensive in the manufacturing process because the energy results were given as a total for the whole manufacturing process. This influenced the results greatly since the impacts in the manufacturing phase depend on the type of electricity used. When hydropower was selected as the source of electricity to manufacture the wind turbine, the negative impacts on the environment would be less. The energy consumption for the manufacture of the wind turbine is the largest impact contributor in various characterization categories. It is worth investigating the manufacturing process in-depth to find out opportunities to improve energy efficiency. It needs to be pointed out that the wind turbines also have a visual impact on the environment. However, due to its subjective nature, the category was omitted.

\section{References}

[1] D. de Renzo, "Vetrojenergetika" [Wind power], [Per. s angl. Zubareva V.V. i Drankfurta M.O.]; Jenergoatomizdat, Moskva, 1982.

[2] Gh. M. Zabarnyj, A. V. Shhurchkov "Energhetychnyj potencial netradycijnykh dzherel energhiji" [Energy potential of non-traditional energy sources], ITTF, Kyiv, 2002, pp. 151-159.

[3] T. Burton, D. Sharpe, N. Jenkins, E. Bossanyi, Wind energy. Handbook, England, 2001.

[4] T. Chmielniak, Technologie energetyczne. Wydawnictwa NaukowoTechniczne, Warszawa, 2008.

[5 ISO 14040 Environmental Management. Life Cycle Assessment. Principles and framework. International Organisation for standardisation: Geneva, Switzerland, 1997.

[6] ISO 14042: DSTU ISO/TR 14047:2007 (ISO/TR 14047:2003, IDT) Ekologhichne upravlinnja. Ocinjuvannja vplyviv u procesi zhyttjevogho cyklu. Pryklady zastosuvannja. [Environmental management. Impact assessment in the life cycle. Application examples], Derzhstandart Ukrajiny, Kyiv, 2009.

[7] DSTU ISO 14040:2004 Ekologhichne keruvannja. Ocinjuvannja zhyttjevogho cyklu. Pryncypy ta struktura [Environmental management. Life cycle assessment. Principles and structure], Derzhstandart Ukrajiny, Kyiv, 2007.

[8] B. Cleary, A. Duffy, A. O’Connor, "Using life cycle assessment to compare wind energy infrastructure", Proceedings of International Symposium on Life Cycle Assessment and Construction, 2012, pp. 31-39.

[9] E. Martinez, F. Sanz, S. Pellegrini [et. Al] "Life cycle assessment of a multi-megawatt wind turbine", Renewable Energy 34(3), pp. 667-673, 2009. doi: 10.1016/j.renene.2008.05.020.

[10] Ch. Chenai, Life cycle analysis of wind turbin. Sustainable Development, Energy, Engineering and Technologies, Manufacturing and Environment, 2012.

[11] T. Toth, S. Szegedi, "Anthropogeomorphologic impacts of onshore and offshore wind farms" Acta climatologica et chorologica 40-41, pp. 147-154, 2000. 
[12] B. Ermolenko, G. Ermolenko, M. Ryzhenkov, "Jekologicheskie aspekty vitroenergetiki" Environmental aspects of wind power]. Teplojenergetika, Moskva, 11, 2011, pp. 72-78.

[13] Andersen PD (7/8.3.2002): Environmentally Sound Design and Recycling of Future Wind Power Systems. In: IEA R\&D Wind's Topical expert meeting on Material recycling and life cycle analysis (LCA) of wind turbines. Risoe National Laboratory.

[14] E. Martínez, F. Sanz, S. Pellegrinia, E. Jiménezc, J. Blancob, "Life cycle assessment of a multi-megawatt wind turbine" Renewable Energy, Volume 34, Issue 3, 2009, pp. 667-673. doi: 10.1016/j.renene.2008.05.020.

[15] Elsam: Livscyklusvurdering af hav- og landplacerede vindmølleparker, 02-170261, Elsam Engineering A/S, Kraftværksvej 53, Fredericia, DK, 2004.

[16] H. Hassing, S. Varming, "Life Cycle Assessment for Wind Turbines". In 2001 European Wind Energy Conference and Exhibition. Tech-wise A/S, Kraftvarksvej 53, DK-7000, 2-6.7.2001, Fredericia, Copenhagen, DK.

[17] M. Lenzen, J. Munksgaard, "Energy and $\mathrm{CO}_{2}$ lifecycle analyses of wind turbines". Review and applications. Renewable Energy 26, pp. 339-362, 2002.

[18] M. Lenzen, U. Wachsmann, "Wind turbines in Brazil and Germany: an example of geographical variability in Life-cycle assessment”. Applied Energy 77, pp. 119-130, 2004.

[19] L. Schleisner, "Life cycle assessment of a wind farm and related externalities". Renewable Energy 20, pp. 279$288,2000$.

[20] Tech-wise A/S: Livscyklusvurdering af vindmøller. 01-488, Techwise A/S, Kraftværksvej 53, Fredericia, DK Schleisner, Tech-wise A/S, 2001.

[21] Final Report. Life Cycle Assessment Of Electricity Production from a Vestas V112 Turbine Wind Plant., 2011. [Online]. - Available: http://www.vestas.com.

[22] T. Bojko, M. Paslavskyi, M. Ruda, "Stability of composite landscape complexes: model formalization". Scientific Bulletin of UNFU, 29(3), pp. 108-113, 2019. doi: $10.15421 / 40290323$

[23] M. Ruda, A. Hyvlyud, V. Lentyakov, "Application of compartment analysis for modeling of environmental influence of consortium ecotones of protected type", Scientific Bulletin of UNFU, 28(6), pp. 60-67, 2018, doi: $10.15421 / 40280612$

[24] M. Stachowicz, Classification and evaluation of life cycle assessment tools. MS Thesis, Faculty of Process and Environmental Engineering, Technical University of Lodz, Lodz, Poland, 2001.

[25] I. Zbicinski, J. Stavenuiter, B. Kozlowska, H. P. M. Coevering, Product Design and Life Cycle Assessment. Uppsala, BUP, 2006.

[26] M. Goedkoop, M. Oele, J. Leijting, T. Ponsioen, E. Meijer, "Introduction to LCA with SimaPro", 2016. [Online]. Available: https://www.presustainability.com/download/ SimaPro8Introduction ToLCA.pdf.

[27] R. Sinha, M. Lennartsson, B. Frostell, "Environmental footprint assessment of building structures: a comparative study." Building and Environment, 104, pp. 162171, 2016. doi: 10.1016/j.buildenv.2016.05.012

[28] O. Pombo, K. Allacker, B. Rivela, J. Neila, "Sustainability assessment of energy saving measures: a multicriteria approach for residential buildings retrofitting". A case study of the Spanish housing stock. Energy and Buildings, 116, pp. 384-394, 2016. doi: 10.1016/j.enbuild.2016.01.019.

[29] I. Zbicinski, J. Stavenuiter, B. Kozlowska, H. Van de Coevering, Product design and Life Cycle Assessment. The Baltic University Press, 4, 2006.

[30] European Wind Energy Agency, 2006. Retrieved on 28/04/2006. [Online]. Available: http://www.ewea. rg/index.php?id=196.
[31] Vestas, 2005, Life cycle assessment of offshore and onshore sited wind power plants based on Vestas V90-3.0 MW turbines. Retrieved on 20/05/2006. [Online]. Available: http://www.vestas.com/pdf/miljoe/pdf/LCA \%20V90-

$3.0 \% 20 \mathrm{MW} \% 20$ onshore $\% 20$ og $\% 20$ offshore $\% 20$ samt $\% 20 \mathrm{e}$ nergibalance, $\% 202005$.pdf.

[32] State Energy Conservation Office (SECO). Retrieved on 01/06/2006 http://www.infinitepower.org/ resglossary.htm.

[33] Vestas, 2004, General Specification V90 - 3.0 MW $60 \mathrm{~Hz}$ Variable Speed Turbine. Retrieved on 20/05/2006. [Online]. Available: http://mainegov-images.informe.org/ doc/lurc/projects/redington/Documents/Section01_Developme nt_Description/Development_Electric/E_Pro_Reports/Appendi x $\overline{\%} 20$ A \%20V90 \%20General \%20Spec \%20950010R1.pdf.

[34] Vestas, 2005, Environmental Statement 2004, Retrieved on 28/04/2006. [Online]. Available: http://www. vestas.com/pdf/news/2005/Vestas2004_Miljo_UK.pdf.

[35] Danish Energy Authority, 2006. Energy Statistics 2004. Retrieved on 21/05/2006. [Online]. Available: http://www.ens.dk/graphics/Publikationer/Statistik UK/Energy _Statistics_2004/html/large01e.htm.

[36] D. Ancona, J. Mc Veigh, "Wind Turbine". Materials and Manufacturing Fact Sheet. Retrieved on 28/04/2006. [Online]. Available: http://www.generalplastics.com/uploads/technology/ WindTurbine-MaterialsandManufacturing FactSheet.pdf.

[37] Battele Clumbus Laboratories, "Energy use patterns in metallurgical and non-metallic mineral processing". As cited in United Nations Centre 1992 on Transnational Corporations, Climate Change and Transnational Corporations Analysis and Trends. Retrieved on 20/05/2006. [Online]. Available: http://www.ieer.org/reports/climchg/ch7.pdf.

[38] Energy \& Recycling. Retrieved on 20/05/2006. [Online]. Available: http://faculty.washington.edu/crowther/ KidsZone/recycling.html.

[39] P. Bezrukih, "Ispol'zovanie jenergii vetra" [Use of wind energyTehnika, jekonomika, jekologija, Kolos, Moscow, 2008.

[40] SimaPro Manuals. [Online]. Available: http://www.pre.nl/content/manuals.

[41] J. Makovecjka, "Ocinjuvannja zhyttjevogho cyklu produkciji jak instrument vplyvu na minimizaciju vidkhodiv" [Assessing the product life cycle as a tool for influencing waste minimization] Elektronne naukove fakhove vydannja "Efektyvna ekonomika", [Online]. Available: http://www.economy.nayka. com.ua/?op=1\&z=1529.

[42] Copenhagen Sustainability Lectures, 2019. [Online]. Available: http://klima.ku.dk/sustainability 1 ectures/inger_andersen/.

[43] R. Plch, O. Pechacek, V. Vala, R. Pokorny, P. Bednar, P. Cudlin, "Energy, carbon and economic balance of Norway spruce monocultures and near-natural forests", in Proc. of the 3rd annual Global Change and Resilience Conference, Brno, Czech Republic, 2013, pp. 50-55.

[44] R. Stojanov, "Climate change impacts and migration in Bangladesh", in Proc. of the 3rd annual Global Change and Resilience Conference, Brno, Czech Republic, 2013, pp. 61-66.

[45] M. Goedkoop, The Eco-indicator 95 (NOH report 9514). Pre Consultants, Amersfoort, The Netherlands, 1995.

[46] D. Van de Meent, J. Bakker, O. Klepper, "Potentially affected fraction as an indicator of toxic stress, application of aquatic and terrestial ecosystems in the Netherlands". 18th Annual Meeting of SETAC, November 1997, San Francisco.

[47] R. Muller-Wenk, Depletion of abiotic resources weighted on the base of "virtual" impacts of lower grade deposits in future. IWO Diskussionsbeitrag Nr. 57, Universitat St. Gallen: Switzerland, 1998. 